\title{
The Attainment Level of Economic Empowerment of Transgender: Flesh Trade Vs. SHGs Activities, Tamil Nadu is a Reference State in India
}

\author{
K.Prabhakar Rajkumar, M.Suguna
}

\begin{abstract}
The ultimate function of the post is to assess the accomplishment degree of economic permission of the Transgender community after they have actually begun Self Support Group (SHG) activities in Tamil Nadu. The research study made a try to review the success of economic empowerment while they are actually performing the physical nature field as well as began SHGs activities. For this purpose, 506 Transgender participants were actually collected coming from 52 SHGs in 32 districts of Tamil Nadu. This study recognized that in what technique the Transgender individuals can remedy for the links from physical nature field as well as exactly how they can create the reasonable earnings coming from the SHGs service started as opposed to doing flesh business and also has sustained their social-economic empowerment in the state.
\end{abstract}

Key words: Transgerder, Economic Empowerment, Income generations, Social Status.

\section{I.INTRODUCTION}

The Transgender neighborhood in India stood for largely by hijras as well as this, has long borne the brunt of male chauvinistic social prejudices and drastic rules that banned different sexuality. This is although that India has a 4,000-year history of third sex and also eunuch cultural 1 . Merely if they take pleasure in easy civils rights, social as well as likewise political, may their self-confidence increase. In India, there are actually approximately one thousand Transgender people along with they are actually towered above as well as they are actually actually gotten rid of coming from culture. The large bulk is actually live in shanty towns along with limited job possibilities. Their standard survival, livelihoods, and everything is actually cleared away and also they are pushed to a worthless daily life. Normally, a lot of the Transgenders are actually taken part in sexual activity job as well as pleading. Transgender in Mumbai participates in a principal function in each of the process arising from beginning till fatality since the people in Mumbai respect it a perk to become honored by the Transgender and additionally they swiftly spend whatever the Transgender needs. Besides this, there are actually actually a considerable amount of other sources for the Transgender to make money. They usually begin obtaining, execute some menial family collaborates with the Jains as well as also help them along with obtaining, while most of all of them are really sexual activity workers.

Revised Manuscript Received on November 05, 2019.

Dr.K.PrabhakarRajkumar, Associate Professor, Department of Commerce, Periyar University, Salem, Tamil Nadu, India.

Dr.M.Suguna, Assistant Professor, Department of Commerce, Periyar University, Salem, Tamil Nadu, India.

E.Mail : kudalkprk6@yahoo.co.in

\section{TAMIL NADU AND TRANSGENDERS}

In Tamil Nadu, there are actually about 60,000 Transgender individuals as well as their socioeconomic and also political condition is actually incredibly unsatisfactory as well as terrible 2. A lot of the Transgenders live as a team with a strong building. Guys who pinpoint themselves as women join the Aravaani area. In a household when the Transgenders are actually recognized they would be actually compelled to leave their home and also community was every bit as un-welcoming and also incredibly few of them are allowed by their family members as well as hence they typically associate amongst themselves regardless of whether living in different locations. Those located quite early are actually thrown away due to the family members and also are actually gotten due to the transsexuals who increase all of them as their personal. It is actually due to the social judgment connected to them Transgenders are actually unable to obtain any kind of form of basic projects. The greatest typical sight is actually to locate all of them slapping their hands and also scrounging in the streets, learns as well as buses. They might swoon on the house that possesses a newborn and would absolutely go just after they take cash from the parents of the kid. Some additionally delight in sex task and additionally minor unlawful acts. A lot of each of them are actually commonly staying in skid row areas and centers in their residences is really extremely poor as well as they are staying in shelters without restroom and also toilet facilities. Typically the variety of Transgender people living in a property is greater than the capability of our residence. Individuals often accomplish surely not choose to have Transgender persons as lessees as a result rental home is testing to obtain. Transgender individuals likewise whine concerning experiencing taunting as well as indignation in social spots. Abusive opinions, citing their sexual preference, are guided at them. Most of each one of them are actually vagrants and/or sexual activity employees.

The battle for constitutionals rights and likewise mainstream of a place including the Transgender region in Tamil Nadu seems the death knell for the practices as well as also practices lug the neighborhood along with one another and also give it a sense of coherence and anecdotal energy. They possessed exceptionally handful of humans rights as well as were really certainly not discovered due to the Indian regulation, which declined every one of all of them the right to vote, very personal property, receive married to and also the right to insurance coverage case qualified identity with any kind of

Blue Eyes Intelligence Engineering \& Sciences Publication 
kind of certifications featuring travel permit or perhaps steering license. Regardless of such options, they were actually required to generate income any way they can.

In South India, they take care of immeasurable obstacles in their daily presence, like barricades to accessing clinical, social judgment as well as sex prejudice. Transgender individuals are actually the oppressed party in the culture They are the feasible target at because of the sizable escalate bias. Transgender people experience an amount of immediate and second bias. The society accosts every one of them along with negative testimonials, communicated, bodily or perhaps sexual assault and even unsafe behaviors. Transgender students are actually frequently harassed along with reduce helpful possibilities when they carry out not follow manners of just exactly how kids and also females must seem or even operate. They are really generally bothered in the workplace and also addressed unjustly in public holiday season cottages, real estate as well as credit history offers. Most of each one of all of them are out of work or even underemployed while bunches of others are really regularly fired through their companies.

Tamil Nadu set up India's very initial Transgender Social Welfare Panel in 2008. This physical body was actually set up in reaction to the outstanding bias and also health dangers faced through Tamil's Transgendered area Tamil Nadu's Transgender Health and wellbeing Panel conducted assignment memory cards for Transgender individuals. The Experts executed ailment demographics to identify in addition to give Tamil Transgendered individuals alongside identity memory cards. One month after the Panel was really developed, the Government gave out a third order, guaranteeing Transgenders made a reservation for chairs in Tamil Nadu's colleges and universities. The Ailment Authorities also supplied lead-in initiatives for assisting the marginalized place. The Condition started measures to develop 'Aravani' (Transgenders) Personal Assistance Teams on the lines of Ladies Personal Support Groups. To promote Transgenders and also marginalized ladies, a microfinance system was released by Tamil Nadu TAI Viluthugal Alliance (TAIVF) under which 16 crews were offered a car loan of.50,000 each. To make sure lasting influence and also resilience, any sort of plan for the discount of Transgenders and marginalized girls's crews to base on their feet, needs to produce independent and additionally help coordinate their lifestyles. The State Federal government has really triggered various measures to improve the way of life of the Transgender area like issuing assignment sd card along with consumer id memory cards. So far 451 land pattas have actually been actually distributed among the Transgender places. Dued to the fact that its own progression in 2014 TAIVF has actually been servicing the microfinance endeavor as well as also has really enlisted around 30,000 people. The participants always kept social set to build a sizable corpus. A complete quantity of of. 21000 has actually been really triggered.8,00,000 was really arranged to 16 teams - each obtaining.50,000. The teams, consequently, will lend car loans to their members to proceed a practical activity to ensure that the loan as well as also the interest might be actually settled to TAIVF. While the Partnership will absolutely provide financings to the Self-Help Groups at 12 per-cent every annum passion, the participants will absolutely borrow at 24 percent expense. The expenses are much lower than what is really announced via other small amount of money business. Having in fact discovered Jan 18 as 'Transgender Time' for the past 6 years, the area has actually currently requested the federal government to officially acknowledge and commit the amount of time as Transgender Day3.

To lessen the sufferings of Transgender, the Tamil Nadu Federal government has in fact taken beneficial actions to help these gender minorities sign up with the regular society and also result in the country's socio-economic innovation. The Tamil Nadu Authorities has actually made an unique Well being Panel and also is really supplying numerous support. Besides this, Economic Assistance is actually being in fact provided to every one of all of them to lead a minimize method of living as effectively as help them accept in the lifestyle. The Tamil Nadu Federal government has actually passed an expenditure in the celebration buying all the Social Welfare Departments in the Condition to make it obligatory to identify the Transgender in each area and additionally begin Transgender Personal Support Staff. Because of the aches and additionally initiatives taken by the Regulators, Micro Financial should help Transgenders in three ways, such as 1 . by industrying second hand schedules and additionally offering individual resources of financial activity along with revenue outside property; mini-credit has a tendency to lower the economic dependancy of the Transgenders in addition to thereby aid to strengthen their freedom. 2. some private income resources alongside their straight exposure to brand-new collections of ideas, worths, attitude, mindset and likewise social assistance need to make these Transgenders far more assertive of their liberties and also 3. microcredit document system by delivering monitoring over worldly sources must bring up Transgenders' eminence and also standing in the eyes of the community and also consequently make certain intersperse appointment also in the neighborhood.

\section{SELF HELP GROUPS IN TAMIL NADU}

Tamil Nadu is actually only some of the prevalent States promoting accumulations of SHGs next to Andhra Pradesh and Kerala. The NGOs along with Banks are using credit score ranking locations to SHGs' members. Nonetheless the parts of NGOs are much higher banks in advertising credit report to insufficient people, since the banking companies are actually certainly not extending this business in the red Typically a Self Assist Team includes 12 to twenty individuals that pick up the instant in a full week to gather quantities from every individual as price cuts as well as the amount is allowed in their profile. The banking company makes it possible for the attendees to take the amount stemming from the financial savings for their specific use for the preliminary 6 months, delivered they repay it constantly in installation. If the team abides to the norms, the banking company progression to supply a direct association finance double the preserving volume along with when delighted with this bargain, it additionally approves financing as high as.5 lakhs with subsidy. This method is actually referred to as Economic Assistance. 
The Tamil Nadu Women's Growth Activity as 'Mahalir Thittam' is a procedure adapted job which sets great importance on the qualitative and also socioeconomic aspect of the progress of women. It is actually an exclusive task based upon courses gotten coming from the implementation of the $\mathrm{x}$ International Fund for Agricultural Progress sustained fly ventures beginning along with 1989-90. The Federal Government of Tamil Nadu along with its personal line team, NGOs and office banks integrated to obtain the goal of socioeconomic permission of females. The objectives of Mahalir Thittam are to generate capacity of negative as well as also denied women to make sure that they manage to cross all social as well as monetary obstacles as well as consequently facilitate their improvement straight into inspired people. Achieve the equality as well as disorder of poor women as individuals, decision makers and called beneficiaries in the democratic, monetary, social and additionally cultural arenas of lifestyle. Make and even restructure self-governing, affordable and social methods in addition to organizations to make it achievable for insufficient women to acquire involved completely and definitely in option making in the family as well as likewise location and additionally at the local, area, state, and nationally level, to equip women to socialize with males, as identical companions, as well as to motivate a brand new production of women and also men to work together for impartiality, maintainable progress as well as additionally typical serenity. Promote as well as make sure the specific right of girls in any way stages of their life process and also supporter modifications in Authorities strategies as well as likewise plans in favor of disadvantaged women.

The goals of the duty are Social permission of girls via Equal standing, involvement as well as also electric energies of decision making at the house degree: equivalent ailment, involvement in addition to energies of selection making at place as well as likewise community levels, beating social, cultural and also religious challenges to get impartiality of disorder and recognition of ladies in their day-to-day parties and additionally on problems stressing each of all of them as well as boosted condition, engagement and also electricity of choice creating in self-governing companies. Economic empowerment of girls using better access to funds outside your house, lowered weak spot of bad ladies in situation cases like destitution, flooding, problem death/accidents in the family, considerable growth and also control over various information at your home amount and additionally the monetary self dependancy of females, both in the residence and also in the outdoors setting. Capacity Structure of girls along with Better recognition of health, learning, setting, legal humans rights etc., enhancement in operational efficiency and also innumeracy, much better industrial abilities in addition to far better monitoring skill-sets as well as discount of self assistance in addition to common assistance.

\section{Inspiring Transgender with Self Assistance Groups in Tamil Nadu}

It is in fact attainable to make employment opportunity for Transgenders to execute projects to carry out particularly economical jobs and social improving. Its intentions are actually enhancement of their skill-sets, capability property, receiving positive self-image as well as participating in decision-making activities after participating in SHGs. There is in fact important to referred to as properly as evaluation the status of work for Transgenders. Their work creation activity via SHGs had in fact integrated brand-new sizes and additionally was actually desiring that they had really been really supporting properly to the national economic health condition. It is really foreseed that employment creation of Transgenders using SHGs had actually produced a longing to be successful as well as likewise want for freedom, self guarantee and personal reliance, derring-do and chance of efficiency, effort behaviors, augmentation of the economical condition, skills, capabilities, originality and additionally management.

Education and learning is a highly effective source to assist the Transgenders to promote themselves. The national strategies of progress had really not reached each of them. They were dwelling in unhappy ailments. They were experiencing reduced education and learning, reduced job, poor health, in addition to social backwardness. The work development program for weaker area was actually not known to the unacceptable folks. Development of Self-Help Groups was in fact the extremely initial dependable technique to split the vicious circle of destitution of people of India. The research study of Transgenders status as well as likewise functionality would definitely subject simply exactly how to create all of them. The research study is actually mosting likely to show the confidence amongst Transgenders, their useful picture of contribution to community, policy and also economic circumstance, their capability to assume significantly, decision-making capacities, and additionally equivalent involvement in the growth method.

Job development of Transgenders is actually a process that handles all sources as well as constructs of electric energy. Learning featuring proficiency and also perspective advancement possessed better project in work generation of Transgenders in cultivating their socioeconomic well-beings. The International Affiliation on Inhabitants Progression 1994 had proposed that understanding was just one of the outright most crucial strategies of appropriately being actually of all humans with the understanding, skill-sets as well as peace of mind needed to have to get included fully in the innovation treatment.

Individual Assistance Group makes social understanding worrying cost-effective development, social welfares and also wellness and health remedies. The criteria for efficiently being in fact of men was actually especially drawn attention as their effectiveness, per-cent was actually just 71.40 per-cent in rural areas and likewise 86.70 per-cent in urban areas as contrasted to the ladies's education by means of 46.70 percent as well as 73.20 per-cent particularly in 2001 in India5. It was actually not the girls merely to become launched for advancement, however, the men equivalents in backwoods were really in addition to be equally cultivated through SHG. Often guys were actually much less upgraded regarding the progression procedure. They were actually asked for to become lively enough to take on financial duties for their advancement. Government programmes for encouraging the weak areas were added considering monetary intend for than physical achievement. The Federal government of India had roused several advancement plans for country individuals. and Engi IJTRE 
The Transgenders were certainly not exemption to provide exclusive electric energy in the financial development technique. The Central Federal federal government alongside circumstances government governments seeks to manage the conditions of inequality of sexual activity connected improvement along with SHGs. The SocioEconomic development of the Transgenders was actually performed with the Self-Help Group in 32 districts of Tamil Nadu in Improving the way of life, providing adequate possibility for all of them to effective activities, Request of the Experts advancement programs, Self is really producing as well as keeping a savings account, adaptability to switch a financial task on purpose, command along with ownership in property or business property as well as residential properties and also joining the loved one organisation for self-rewarded. The progression of guys welcomed the method of producing self-reliance as well as also self-sufficient. The method of self-sufficiency was in fact an on-going method by means of: providing every one of all of them discussed assistance for family well-being, creating approaches to overcome their problems and additionally bring up awareness of education, publication of knowledge for well-balanced nourishment, family members well being as well as also legal civil liberties. The transgender Personal Assistance Team is commonly identified as "Exclusive Team". Unlike Non - Transgender Self Aid Staffs. They can easily work in spite of 5 participants. The head of state, treasurer as well as likewise Secretary are responsible for keeping the accounts in 7 Ledgers. Economic Assistance in addition to Revolving Fund is in fact allocated to all of them. This program gives every one of them with.25,000 which need to be in fact settled totally with no setup as a result of. As the title reveals, the plan gets every one of them for 6 opportunities in addition to.10,000 aids. A Transgender group of Kurinji Malar at Coimbatore along with 12 individuals was actually taken part in serving service as well as additionally had actually gone through training at Avinashilingam University. For every single job the crew conducted it put in.90,000 in the direction of tapping the services of tools and additionally right now it might conserve that quantity, as it could make use of the aid funds.5 lakh to acquire vessels. There is a probability of tapping the services of the ships to much more improve incomes. Ms. Sangeetha the leader of the group pointed out that the region management had actually stepped forward in alloting pair of buy the Poomalai shopping mall to the team to operate buildings. There the staff will expose collaborate with the ships as well as likewise market food items packages. A harsh calculation of its income and also sets you back subjected that each employee can create roughly.5,000 a month, likewise after spending.2,000 towards servicing the car loan. She likewise explained that the aid originating from the collaborative organizations would certainly go a long way in supplying economic self-direction and also the much-needed social acknowledgment. As well as, so much more notably, it would certainly perform as a case for other individuals of the Transgender area to use up financial duties. Hon' ble Chief Minister of Tamil Nadu Dr.J.Jayalalithaa, has in fact revealed that the Thirunangaigal (Transgenders) Individual Assistance Groups will definitely be actually created and likewise fiscally maintained in addition to a best roof of.15 Lakhs for plunging into livelihood as well as economic activities6.

\section{ASSESSMENT OF LITERARY WORKS}

Transgenders have numerous troubles in beginning SHGs tasks in Tamil Nadu. In 2003, a crew of Aravani girls that had actually functioned in the HIV industry decided to handle an NGO in the Theni Region of Tamil Nadu phoned Arogya Agam, assembling Private Help micro-finance teams and additionally local business for Transgenders females. When seeking to register the establishment, they were actually alerted that without a bank account, provision memory card or electrical power costs to verify their identifications, they will certainly not have the capacity to register Arogya Agam. As Transgenders girls, they would be in fact unable to obtain principal forms of id? Considered that they reveal by themselves as ladies however are in fact persuaded to get in touch with on their own guys for the sake of legal i.d., their documents have no credibility. The major concern is they are really also substandard in the aspect of lader helpful to all of them and if there is really an ideal economic as well as additionally focused support to each one of them they prepare to cultivate SHGs as well as to accomplish organization 6. The Vetri SHG made certain through Swami Vivekananda Gurukulam (SVG), Coimbatore is a prosperous Personal Support Staff generated along with gone through Girls participants as well as it is actually funded by State Financial institution of India, SRKV Branch at Coimbatore. The overall amount of attendees in this specific team is really 17 and 15 of all of all of them are associated with a recovery agent activity. The funding availed was actually to the purchase of.5.75 lakh, which was actually taken advantage of for doing business consisting of in groceries, dark chocolate agency, garlic solution, saree sales, and so on. The staff possesses actually thus far spared.2 lakh7. Transgenders' Support group need to provide a haven for all of them to please offering members different types of assistance. Some teams are assisted in by means of a professional social worker or even psycho therapist and also supply specialist encourage. Transgender peer self-help group are really non-professional along with discuss a commonality where suitable facts and also exclusive expertise might be actually talked about in between the members of the group. A Transgenders' Self-help Group can be the one location where an individual can have their idea and also sensations as well as problems vocalized to an understanding audience, paying attention very closely to different other's stress and evaluating those problems. The self-help group happens a social media network where a Transgender personal no more feels split up. Various Transgenders' Self-help group function to instruct the community about Transgender difficulties along with an advocate for the Transgender community8. The Senthamizl Pavai Mahalir SHG made certain by means of Girls Institution for Rural Growth (PLANET), Cuddalore is really a reliable Personal Aid Crew formed and also dealt with through Gals members and additionally it is really spent for through Ailment Bank of India, Manapattu. The interview revealed: Ladies Company for Rural Innovation (PLANET) was really made it possible for through NABARD's sponsorship of.90,000 in March 2005 for promo in addition to credit rating linkage of fifty all new SHGs around Cuddalore Block, in Cuddalore district9. Brahan nayaki, a 48 years of age girl of 
Vadapuram Keelpadhi was actually remaining in a very insufficient affordable disorder and her partner has a casual electrical outlet as well as had handed to oral cavity visibility. She discovered the SHG as well as also through the NGO, she assembled 19 participants, that also concerned below poverty line group. Everyone of every one of them were landless as well as additionally a number of the members were actually working as agricultural laborers, that too in periods. Each of each one of all of them have in fact bought one critter each via Private Aid Teams and also are actually giving milk to the dairy programmers lock up neighborhood in the city. Their take-home pay has in fact gone upto to.1,500 per month every participant. They have cleared about fifty percent of the lending. On noting the on schedule settlement the division supervisor very recommended TEAP-RF lending of.45,000 (that consisted of.30,000 aid in addition to.15,000 car loan part). The group's markdowns as on time is in fact.1.20 lakh as well as additionally their internal funding is to the order of.3.00 lakh. The Subam SHG marketed by Hand in Hand, Villupuram is a reliable Self Support Team produced as well as likewise dealt with through Females members and also it is spent for by means of Pallavan Grama Financial Institution, Villupuram. The members were actually make known the beneficial and also misfortunes of the participants in the team. Subam SHG at Tindivanam was actually created by Hand in Hand, Tindivanam, Villupuram area on 5 January 2005 along with fifteen individuals. These individuals participated in an Eventually Awareness Program conducted due to the NGO, Hand in Hand alongside NABARD's give aid. After recognizing the Computer device skills of five members of the SHG, Together determined all of them to start a personal computer facility. The Pallavan Grama Banking company provided.2 lakh auto loan to five participants viz., Kanchana, Prema, Valli, Divya and John to start the institution. They acquired 5 home computers as well as additionally an ink-jet printer. These SHG members carry out instruction programs, particularly for poor and downtrodden gals as well as underprivileged little ones. The plans supplied as a result of the Facility include Degree in Office Automation, Diploma in Pc Functions, Diploma Or Degree Or Degree in Typesetting, and so on. The group participants make a month to month earnings of.12,000 to.15,000 10.

In addition the Researcher hoped that the idea of Personal Support Teams can improve the Social Progression of Transgenders in the way of: Drinking "we for our" concept among Transgenders. Takes sameness among Transgenders and also reduces the difference of caste as well as religious beliefs as well as increases the social as well as also wellness awareness one of Transgenders. Involvement of Transgenders to satisfy the essential criteria of nation lifestyle obtains enriched. Involvement of Transgenders in democratic activities as well as Panchayat system obtains increased may market Transgenders participation in obliteration of social conditions like bodily brutality versus them. Offer initiative for general knowing to Transgenders Developing understanding of lawful liberties and additionally legal aid availability to free Transgenders arising from exploitation. Therefore there is not one other method of Socio Economic Growth of Transgenders without the concept of Self Help Staff. Changing Viewpoint (2012) mentions that integrating right into society unconfined along with uncovering a project remains to be a problem for Transgenders in the metropolis, but they have actually not dropped hope. As an alternative, they have in fact begun situating self-reliant, remarkable techniques of making an income. Transgenders in the urban area have really been actually operating in Personal Assistance Groups together with the hope of introduce some loan and also finding yourself being fiscally independent. Vasantham, Vanavil as well as likewise 7 Fate are in fact 3 such teams that are aiding gear up way of lives. In The Beginning S. Sudha, like every other gal, measured right into the Bharatiyar SHG for girls in Porur, where she kept. She found out the tips of the task, nonetheless definitely experienced that a ton of like her were undoubtedly not blessed sufficient to be element of an identical team. "All the gals in my neighbourhood were fast friends along with considered me one among them. Nevertheless then I found out to carry on and also develop a group which possessed just Transgenders," she explains. In addition to 7 attendees and additionally a finance of.1 lakh, she founded the SHG 'Seven Fate'. Members used up palm task, porcelains in addition to glass artwork and also marketed the items created. Some SHGs get items in wholesale and also market every one of them to outlets. Komathi of Vasantham offers saris while her good friends market treats as well as a variety of other meals products. This substitute profit protects against each of them stemming from begging or perhaps needing to office sex. The group 7 Fate was actually used 64 marks through banks authorizations. "They educated our crew that our negotiation was better than many mistress's SHGs," states Sudha. Like any type of company, they possess their slim times and likewise opportunities when they have made fantastic earnings. The teams sell hand crafted items at programs as well as different other places where people set up. While such efforts produce them a little a lot more favorable concerning moving ahead in a community that possesses, for long, been really aloof to all of them, the girls are additionally exerting to become part of the females's Individual Help Groups 11.

\section{STUDY SPACE}

There has actually been actually a lot of valuable study focuses on personal work in addition to assessment of the economical status of Males as well as girl attendees in the Personal Support Groups in numerous disorders in India take advantage of random sample relevant information and all of all of them present an amount of personal employment opportunity. Having said that, none is of an in depth research study worrying the Transgender attendees in the Personal Aid Teams and also their socioeconomic standing in India and even in any kind of particular condition. This is the only research study to which aims to take a look at the great and also harmful effect of socioeconomic effectiveness of Transgender attendees through legal in addition to against the law organisation jobs. There has in fact been some study team up with the standard impact of joblessness in the culture as well as also really small amount of investigation study has been really performed on the impacts of amongst the weak part like Transgender in the society. As far as researcher's experience goes, this is really the only research targeted to examine the here and now socioeconomic in addition to political status of the Transgender individuals as well as find out the permanent restorative services to eliminate all of them originating from the dog's lifestyle. 


\section{IMPORTANCE OF THE STUDY}

Individual self-regard depended upon the recognition of the tangible as well as religious stability of the individual. It is harmed when folks and additionally teams are actually marginalized, paid no attention to or perhaps undervalued. Transgender person performs not take pleasure in the all-natural perks of his/her acquired gender. Such people are actually rejected public and also political rights and might refrain from doing characteristics others conduct, like to uncover mainstream job, vote, joined, get residential property or even handle a child. Steered to the side as social derelicts, they need to have to beg, dance or even carry out sex work for survival. The prejudice versus Transgenders absolutely not simply started along with their residence, yet additionally coming from neighborhood.

The primary concern in the society is in fact that there is in fact no correct awareness and also understanding of the Transgender community along with a lot of each of them are in fact decreasing even they are folks. The common people tower above them as they are actually sex staff members along with scammers. On another edge, the Transgenders are actually hostile versus the lifestyle when the typical respect is in fact refused because of the community and also when they acquire ill-treatment coming from the community they subject their big-headed activities to get themselves. At the Government viewpoint, also the Regulators has really taken a ton of systems acquiring with every one of all of them; the entire advantages not reach each one of all of them appropriately. A lot of lending institutions hang around to offer financial resources to all of all of them, given that they perform not have ideal earnings as well as status in the community.

When the public isolates each one of them, the Authorities disregards them as well as Banking companies do not hope on them, they certainly never leave behind arising from their regular company tasks and also their existing lifestyle. Within this condition the culture should change its personal method of assuming in the direction of all of them and just when the Transgenders absolutely acquire their socioeconomic and also political development and this is actually feasible simply when there is really a correct bodily, mental and also financial backing to the Transgender community.

As a result, the society should take the most affordable needed actions that have to be enjoyed the treatment of eventually blending the Transgender neighborhood right into the mainstream. If they intend to achieve all their social advantages, they must boost their social as well as financial standing. When their financial condition enriches, all various other social factors need to have to furthermore instantly boost. This will definitely take place when the Regulators, Financial Institutions as well as also community lengthen their general support to each one of all of them in every parts as well as likewise give them the chance to create or start any sort of kind of authorized business activities. These are really just beginning of an experience that our company are mosting likely to proceed till essential regard and likewise self-respect to members of the neighborhood are made certain in regulation and also for this the society must affect its attitude. The purposes of the research study are to determine to what level the principle of Personal Help Crew aids the Transgenders to begin any kind of sort of legal company and also coming from Personal Aid Crews in Tamil Nadu In addition to that, the study concentrates on the necessity as well as additionally worth of monetary as well as non financial support to generally properly being actually and permission of the Transgenders in Tamil Nadu.

\section{OBJECTIVES OF THE RESEARCH STUDY}

The general target of this particular analysis is to comprehend far much better the renovation of the socioeconomic electric power of Transgenders via Self Help Teams in Tamil Nadu. The certain objectives of the investigation study are actually offered below:

1. To produce a complete analysis study concerning the Transgenders in Tamil Nadu as well as assess their current socioeconomic standing.

2. To review the job and also financial success of Transgender participants in Self-Help Groups.

\section{STUDY PROCESS}

The analysis study abides by the poll procedure. The analysis wants to find empirically the feature of the partnership in between the socioeconomic progress of Transgenders and buildup of Transgenders' Self Aid Groups as well as its own influence on the general socioeconomic development of Transgenders in Tamil Nadu. The study abide by a private conference as the tool of set of questions making use of a job interview schedule. 506 participants have actually been actually selected as clarified in the part of sampling, from 1,490 Transgender attendees in Personal Help Groups operating in 32 areas of Tamil Nadu. Records connecting to socioeconomic growth as well as other factors just before as well as after the Transgender participants signed up with SHGs have actually been in fact acquired. Interpretations have really been helped make as well as additionally finally pointers have really been actually generated to boost the functions of the Transgender Self Support Crews.

\section{INFORMATION RESOURCES}

The primary data were actually gathered along with the job interview timetable in addition to the vernacular variation as well as marketing study dialogues. The job schedule was actually prepared along with an extensive evaluation of literary works as well as keeping in view the purposes of the research. Pre-testing was really executed on a sample of 51 Transgender attendees in Self-Help Groups as well as also after pre-testing the timetable was in fact re-drafted and also utilized for documents collection. The extra details important to Transgenders' Self-Help Groups were collected coming from the Directorate of Social Welfare Office, Chennai and additionally 32 regions in Tamil Nadu. Required valued appropriate details concerning the Trasgenders' lifestyle in addition to their habits have actually been in fact accumulated in person coming from Transgenders in the 32 districts in Tamil Nadu as well as a few other information from Taiviluthugal Association. Some leading Tamil handbooks, entitled, Aravanigal (Udaliyal, Ulaviyal, Valviyal), Moondraam Paalin Mugam, Thirunangaigal Valviyal matrum Eraieiyal, Thirunangaigal Ulagam were additionally used to acquire some useful information. 
The duration of research study was actually 2 years from 2018- 2019.

\section{CONCEPT}

This research study is actually related to socioeconomic improvement of Transgenders in the Personal Aid Teams and has embraced the multi stage tasting procedure. To begin with, the number of SHGs created and also their handle in the 32 areas was actually picked up from the Directorate of Social Welfare Office found in the area worried. Some time snowball technique was taken on to learn peer Transgender SHGs in the district. Among the 32 districts, 52 SHGs have been actually picked out of 162 applying purposive tasting the reason achieving success performance. This is stage pair of. All the 506 Transgender members in the above 52 SHGs have actually been actually chosen as respondents using the census method in the third as well as last stageThis study is actually associated with socioeconomic renovation of Transgenders in the Self Support Groups and also has actually adopted the multi stage sampling procedure. Initially, the variety of SHGs developed and their deal with in the 32 areas was gathered from the Directorate of Social Welfare Workplace found in the area worried. A long time snowball method was actually embraced to find out peer Transgender SHGs in the area. One of the 32 districts, 52 SHGs have been picked out of 162 using purposive sampling the reason prospering performance. This is stage pair of. All the 506 Transgender members in the above 52 SHGs have actually been actually selected as respondents utilizing the demographics strategy in the 3rd as well as last stage.

\section{Table 1- Sample Size Details}

\begin{tabular}{|c|c|c|c|c|c|}
\hline SI.No & Districts & $\begin{array}{l}\text { No. of } \\
\text { SHG's } \\
\text { Formed }\end{array}$ & $\begin{array}{l}\text { No. of } \\
\text { SHGs } \\
\text { Members }\end{array}$ & $\begin{array}{l}\text { Selected } \\
\text { SHGs }\end{array}$ & $\begin{array}{l}\text { Selected } \\
\text { No. of } \\
\text { Members }\end{array}$ \\
\hline 1. & Arryalur & $\overline{21}$ & 220 & 1 & 10 \\
\hline 2. & Chennai & 6 & 32 & 4 & 24 \\
\hline 3. & Coimbatore & 13 & 110 & 3 & 42 \\
\hline 4. & Cuddalore & 9 & 85 & 1 & 12 \\
\hline 5. & Dharmapuri & 3 & 30 & 1 & 12 \\
\hline 6. & Dindigul & 5 & 60 & 3 & 38 \\
\hline 7. & Erode & 5 & 32 & 3 & 16 \\
\hline 8. & Kanchipuram & 4 & 40 & 1 & 10 \\
\hline 9. & Kanniyakumari & 3 & 32 & 1 & 12 \\
\hline 10. & Kanur & 5 & 38 & 1 & 11 \\
\hline 11. & Kriahnagin & 2 & 24 & 2 & 24 \\
\hline 12. & Madurai & 6 & 75 & 1 & 5 \\
\hline 13. & Nagapattinam & 5 & 44 & 2 & 18 \\
\hline 14. & Namakkal & 10 & 102 & 1 & 6 \\
\hline 15. & Nilgiris & 3 & 18 & 1 & 6 \\
\hline 16. & Perambular & 6 & 30 & 1 & 19 \\
\hline 17. & Pudukkottai & 1 & 7 & 1 & 7 \\
\hline 18. & Ramnathapuram & 2 & 18 & 2 & 18 \\
\hline 19. & Salem & 5 & 55 & 1 & 6 \\
\hline 20. & Sivaganga & 2 & 20 & 1 & 9 \\
\hline 21. & Tiruvannamalai & 3 & 50 & 1 & 7 \\
\hline 22. & Tirunelveli & 5 & 35 & 4 & 20 \\
\hline 23. & Thanjavur & 3 & 45 & 1 & 15 \\
\hline 24. & Theni & 5 & 45 & 1 & 10 \\
\hline 25 . & Tiruvallur & 10 & 85 & 1 & 16 \\
\hline 26. & Tiruvarur & 1 & 8 & 1 & 8 \\
\hline 27. & Tiruppur & 2 & 23 & 1 & 11 \\
\hline 28. & Thoothukodi & 5 & 35 & 1 & 7 \\
\hline 29. & Tiruchirappalli & 4 & 54 & 2 & 24 \\
\hline 30. & Vellore & 6 & 52 & 1 & 10 \\
\hline 31. & Villupuram & 11 & 108 & 4 & 54 \\
\hline 32. & Virudhuagar & 10 & 78 & 2 & 19 \\
\hline & Total & 162 & 1.490 & 52 & 506 \\
\hline
\end{tabular}

\section{XII.Employment and also Economic Achievements through Transgenders' with Personal Aid Teams in Tamil Nadu}

Tamil Nadu is actually the only Shape in India that has really been actually provided a gender standing to transsexuals. In Tamil Nadu one of one of the absolute most greatly seated types of disparity established right in to the framework of regular societies is in fact based upon gender. Gender impartiality has found yourself being actually a specific right worry. It visualizes a brand new alliance in between various other sexual activity and additionally Transgenders based on mutual respect, obligation sharing, the same flow of information and also electrical power formula. In a lot of societies all over the world, Transgenders are preyed on by law and also personalized, leaving each one of them at risk and likewise robbed social groups.

The Tamil Nadu Government has in fact taken a lot of innovation activities as vital to long term destitution easement in property health conditions as consent, in its own widest sense of leading to private reliance of the Transgenders. Thus the suggestion of "one for all plus all for one" is a main item to remove the weak point of Transgenders in the Condition. When the Transgenders receive the socioeconomic status, they might effortlessly join the community and also may quickly discuss their sights and likewise viewpoints. Once they plant social tasks they can rapidly teach by themselves as well as additionally inevitably they may appreciate all social legal civil liberties as well as benefits in the society.

Thus the analyst took an effort to concentrate on the improvement of Transgender activities at the territory origins as well as the impact of socioeconomic Growth of the members of Personal Help Staff in relations to gain access to of bad to institutional credit score document, profits producing tasks started, work creation, an increase in revenue quantity and also complete Socio Economic Development. The economic success with Transgenders along with Personal Aid Teams in 32 Areas of Tamil Nadu are really detailed and additionally taken a look at below.

14. Tracking: Throughout the investigation amount of time, all the 1,490 attendees were actually linked with various company duties like 1 . Cloth marketing 2 . Cow and goat rearing 3. Acquisition of extravagant items, cosmetics things as well as CDs 4. Purchase of fish, vegetables in addition to fruit products 5. Running road food things stalls, cooking meals and vessels discharging company 6. Agricultural duties, emu and fowl farming 7. Taking mango as well as additionally tamarind plants on lease 8 . Offering public dance series, 9. Dairy farm, 10. Utensil organisation, 11. Serving purchases, 12. Producing, thirteen. Dry fish and also flour sales, 14. Paper napkin production, 15. Garments using, 16. Washing detergents developing, 17. Canteen, 18. Stationery channel and also Beauty parlor, 19. Minor channels, twenty. Beedi and also phenols producing, 21. Creating as well as likewise offering of masala things. In addition to a very couple of participants in Salem as well as also Villupuram areas continuing to be actually participants that were connected to Personal Assistance Groups were actually certainly never happy to continue their aged flesh field and additionally begging. In the whole Tamil Nadu 34 per-cent of the Transgenders were spared the clutches of prohibited 
company. 3,455 Transgenders that had actually gone through surgical procedure to be changed as women in addition to enlisted along with the District Social Welfare Department and also the non provided Transgenders signed up with NGOs as well as produced 162 Private Help Teams. The Area Social Welfare Departments handed out 2,555 I.D. memory cards as well as 1,041 distribution memory cards to Transgenders that have in fact carried out procedure to exchange the feminine. A lot more, they have distributed 107 personalizing equipments along with accessory technology and also launched 799 entirely complimentary real property stories to accomplish private organization and also develop the standard of living of trandgender in the Ailment. The Area Social Welfare Departments distributed aid of.64,00,000 to Transgenders group in each the 32 regions and also each team acquired.2,00,000 as well as a financing of.65,90,000. When the 506 sample members were in fact joined flesh trade as well as pleading, their gross income was actually.1,05,60,900 each month. Their net earnings coming from these line of work were actually.39,45,390 after committing.66,15,510 as trade advertising and marketing costs (clothing and also cosmetics costs). Each member may acquire.7,797 month-to-month using physical nature company and additionally pleading. The total net earnings of 506 participants' on gross earnings were 37 per-cent as well as they were actually surely not conserving mindset when they were really involved in physical nature occupation and also asking.

After joining SHGs, the participants can easily gain.26,01,510 a month after devoting.16,64,558 as trade expenses. The team's gross earnings were.42,66,068. Each participant could possibly gain.5,141 a month with SHGs. The teams' net earnings on gross earnings were actually 61 per-cent. Furthermore all the example individuals had the saving perspective and additionally they can use less.72,700 per month after registering with SHGs in addition to each participant's conserving volume improved coming from.0 to.144 month to month. The attendees' financial month to month remittance capacity likewise brought up originating from.0 to.95,764 also after fulfilling their home expenditures. Even though the net earnings of the participants stemming from SHGs were in fact less than 34 per-cent reviewed to earnings stemming from flesh profession as well as begging, the net earnings on gross earnings coming from SHGs were actually 24 percent greater than the one a posteriori.

In the 32 areas in its own entirety, all the 506 members' overall affordable achievements, prior to and also after joining Private Assistance Groups were assessed in the elements of brought up incomes as well as individual employment, acquiring personal home, enriched buying electrical power of building energies, great garments, jewells, premium food items, saving viewpoint as well as resources of cash loan. The general influence of all these answers obtained all of them good life and also public recognition. In the above declared aspects, before participating in SHGs, 70 percent members were in fact really decreased increasing superstars, yet after signing up with SHGs, thirteen per cent members were actually remarkably higher up-and-comers.

Thereby, the researcher pertains to the conclusion that via empirical as well as also statistical explanations, off of 506 Transgender members, 183 were actually produced, 131 were really pristine and also 192 were created in Socio Economic
Advancement in Tamil Nadu As a result, the analyst firmly experiences and likewise supports that Personal Support Groups are actually the only panacea for the Socio Economic Growth of Transgenders in Tamil Nadu.

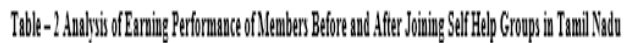

\begin{tabular}{|c|c|c|c|c|c|c|c|c|c|c|c|c|}
\hline \multicolumn{8}{|c|}{ 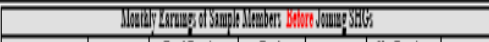 } & \multicolumn{5}{|c|}{ 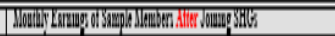 } \\
\hline 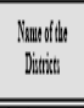 & 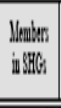 & 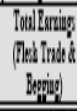 & 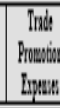 & & & 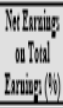 & $\begin{array}{l}\text { Siring } \\
\text { bibulate }\end{array}$ & 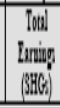 & $\begin{array}{l}\text { Ind } \\
\text { lyom }\end{array}$ & IVI & 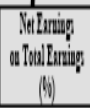 & $\begin{array}{l}\text { Sing } \\
\text { lubate }\end{array}$ \\
\hline$\sqrt{672}$ & iv & WW, & (IXI) & & WWW & W67. & & 6.9.20 & IXIN & 464 & WW: & IXIX) \\
\hline$=$ & 8 & 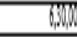 & प्2: & & (bi) & $\mathbb{M}$ & & 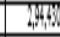 & 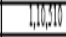 & 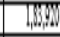 & 76,5 & $x_{\mathbb{N}}$ \\
\hline$=1$ & 4. & 10,901 & 6,99 & & (1), & $3 \mathrm{MT}$ & & (1) 1964 & 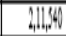 & $3,1,1212$ & 6.2 & 14,4 \\
\hline 世in & . & WW0 & $1,4,1$ & & WOW & W: & & 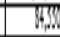 & 32650 & $\mathbb{T I N W}$ & $\mathbb{7 l W}, \mathbb{N}$ & $7, \mathbb{N}$ \\
\hline DExth & II. & WSO & [ISI] & & I2WW & 367? & & WIIIII & 30,602 & 4Q11 & $61,4.4$ & 240 \\
\hline$y$ & II & WTD & IIS & & (III) & 3X:2 & & W62:2 & $\mathbb{Q}, 0, \mathbb{N}$ & WSIIIII & 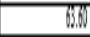 & $\mathrm{IX}$ \\
\hline$E$ & 76 & 1120 & 1819 & & $\mid(1,1)$ & 3! & & 8,60. & $3,0 \%$ & 18,612 & 61.2] & IN \\
\hline Fingen & III & 1,810 & [112. & & IISOM & (30) & & 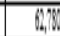 & 8510 & 1810 & 69! & 20 \\
\hline $8=2 x$ & 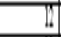 & 1950) & 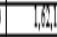 & & $\mathbb{N}=\mathbb{W}$ & III & & ND, & 3,300 & WWE & 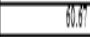 & $t_{4}$ \\
\hline ta: & 4 & $|| 1||$, & {$[1,1.2$.} & & Q B, & 316 & & 69,4 & I690 & 694 & 61.4 & {$[, \ldots$,} \\
\hline tatis & 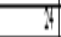 & 3. & WIT & & (Mini & 7NR & & 19.24. & प3m & W.M & WL! & 4 \\
\hline Thini & . & 1,80 & 8,4 & & 4,2, & $\overline{313}$ & & $\$ 96$ & 3878 & 388712 & QND & ] \\
\hline Textam & $\mathbb{T}$ & 7500 & 1,46 & & {$[0, W$} & प15]. & & WMO & 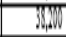 & TMM & FIDS & ISW \\
\hline$\sqrt{x-3}$ & 6 & 1,800 & 76 & & $4 ; 0$ & BIL & & 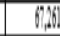 & 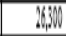 & 4,966 & 60.9 & t. \\
\hline$\sqrt{x+3}$ & & IIIN & $\mathbb{T}$ & & SWD & IIV & & 4,2 & IIST & WW & (DIII & $\pi$ \\
\hline $\mathrm{Rm}$ & $\mathbb{T}$ & 1880 & 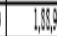 & & Q, 1,10 & $\overline{313}$ & & 1,936 & 1,640 & 8696 & [0.6. & $1+$ \\
\hline $\operatorname{ses} 2$ & & 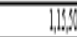 & $\sqrt{110}$ & & 4,0, & $\sqrt{18 .}$ & & 4.,4 & 1,60, & 184. & 61.717 & it \\
\hline 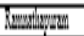 & 181 & WT, & 78 & & $(\mathbb{D P}, \mathrm{W}$ & W & & $7,1,2$ & 9,90 & 73,4 & 7N. & $i$ \\
\hline Situm & 7 & $\|, 17 \%$ & 4 & & 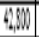 & $\sqrt{36}$ & & 4,6 & 19,00 & $\sqrt{1 / 66}$ & [IIS] & 111 \\
\hline 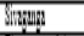 & 7 & (152) & 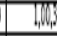 & & Di, & 38 & & WISP & WW & 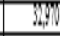 & MQN & II \\
\hline Istumin & & 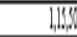 & $\sqrt{34}$ & & LID & $\sqrt{162}$ & & $4,1.11$ & 1,64 & V6: & (16.4. & t) \\
\hline Inetiti & $\mathbb{X}$ & WDON & 67. & & (WWW & 308 & & TWNDI & 7,600 & 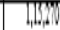 & 60.5 & ? \\
\hline 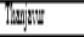 & T. & WDEN & $\sqrt{14}$ & & 8,0, & 38. & & 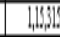 & 4,30 & (3) & QD.6.6 & 4 \\
\hline Isain & w. & ISON & $\overline{M N}$ & & W.15W & 362 & & 6,062 & 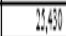 & 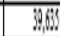 & W:I & IT \\
\hline IEm & 76 & 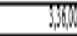 & III, & & (IX), & 376 & & $7,4,4,2$ & (69, & 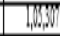 & 70.54 & it \\
\hline $1 \mathrm{sent}$ & 7 & 1,201 & $\sqrt{111}$ & & II, & $\sqrt{186}$ & & 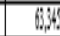 & 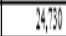 & 38,614 & Q14. & ? \\
\hline IExy & III & 164: & Thin & & (X6060) & 3.1. & & $7,0.2$ & 9860 & 4रा & 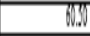 & $\pi$ \\
\hline 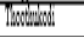 & & 1364 & 81 & & $\overline{s, 1, \infty}$ & $\overline{317}$ & & 183.1 & IMN & 3,14 & 626 & \\
\hline Texnew & 8 & WWW & 3,4 & & WWWW & 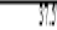 & & tha. & $1,1,9,0$ & 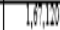 & 6.5 & 5 \\
\hline $\mathrm{VANGI}$ & Tiv & 1,190 & IIII) & & E,W & $\overline{716}$ & & 804 & $3 \|, W$ & $\sqrt{164}$ & (2)18 & 8 \\
\hline 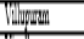 & 7 & 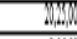 & 1,148 & & (2), & T/. & & $(1962)$ & W19M0 & 3,128 & 7).2 & ? \\
\hline Intures & DIt & 1364) & $\sqrt{16}$ & & - & 36 & & 10801 & ASM & (1) & IIII & $\mathbb{1 1}$ \\
\hline
\end{tabular}

Table -3 Statement of Difference in Net Earnings between Before and After Joining Self Help Groups in Tamil Nadu

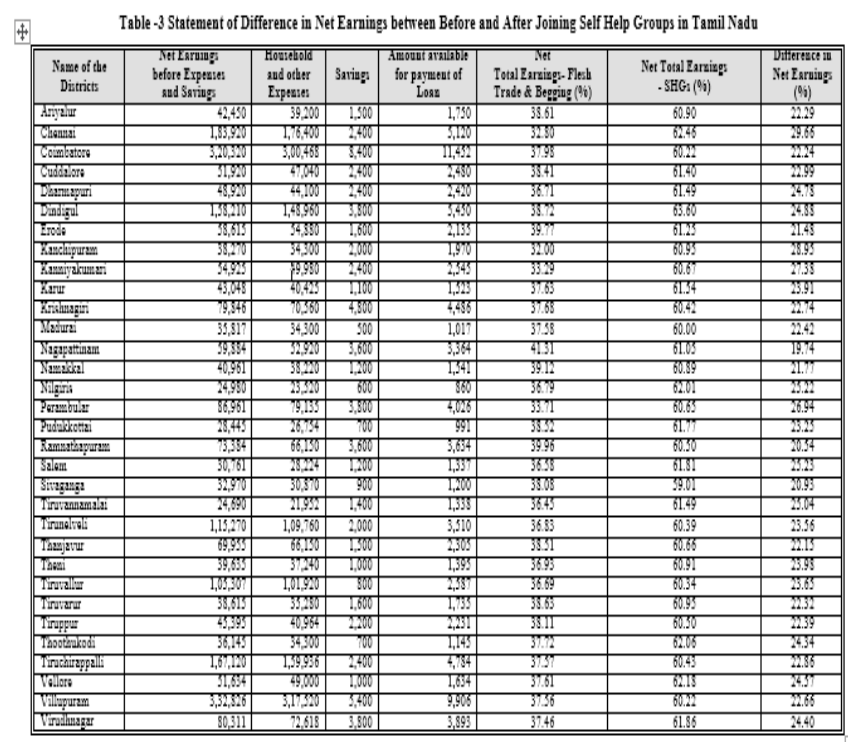


Table - 4 Statement of Overall Attainment of Transgender Members in Tamil Nadu

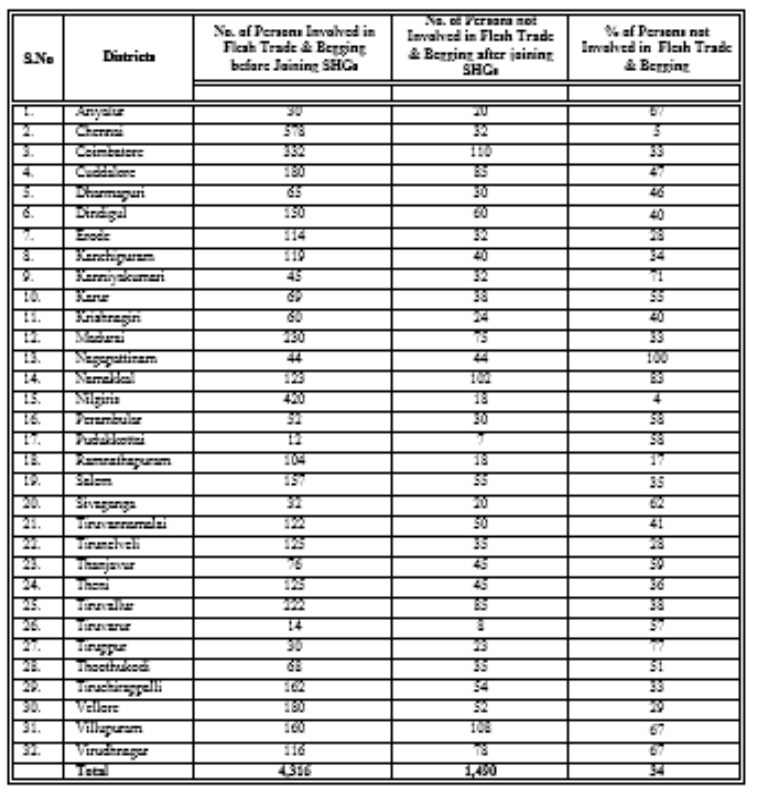

Table -5 Activities of Self Help Groups in Tamil Nadu

\begin{tabular}{|c|c|c|}
\hline $\begin{array}{l}\text { S. } \\
\text { no }\end{array}$ & Districts & Main Activities of members in SHGs \\
\hline 1. & Arivalur & Cloth business, cow and goat rearing and Milk business \\
\hline 2. & Chennai & Sale of fancy and cosmetics items, cloth, fish and vegetables business \\
\hline 3. & Coimbatore & Cooking, street food stalls and vegetables and fruits business \\
\hline 4. & Cuddalore & Coir making, milch animal, cloth vegetable sales, emu farm, CD sales \\
\hline 5. & Dharmapuri & Cloth and saree business \\
\hline 6. & Dindigul & Hotels, vegetable, agricultural activities mango and tamarind lease \\
\hline 7. & Erode & Cloth business, vegetable sales, cultural performances \\
\hline 8. & Kanchipuram & Milch animal and agricultural activities \\
\hline 9. & Kanniyakumar & Cloth business, fish and vegetable sales \\
\hline 10. & Karur & Dairy farm, utensil trade \\
\hline$\frac{11 .}{11 .}$ & Krishnagiri & Milch animal vegetable sales \\
\hline 12. & Madurai & Tailoring, vesgel and vegetable gales cloth and catering business \\
\hline 13. & Nagapattinam & Tiffin shops \\
\hline 14. & Namakkal & Cloth, flower, and fruit business \\
\hline 15. & Nilgiris & Vegetable and fish sales, cow rearing and Milk business \\
\hline 16. & Perambular & Cloth and preparation of cooking masalas and Vegetable sales \\
\hline 17. & Pudukkottai & Cloth and fancy item sales, dry fish and flour sales \\
\hline 18. & Ramnathapuram & Napkin making, cooking vessels let-out and allied items \\
\hline 19. & Salem & Coir twisting, cloth business, flower business, Tiffin shops \\
\hline 20. & Sivaganga & Cloth and fish sales, vessels let-out, Dance performances \\
\hline 21. & Tiruvannamalai & Tiffin shop, fancy materials shops \\
\hline 22. & Tirunelveli & Garments, washing shops making, dance performance \\
\hline 23. & Thanjavur & Flower and fruit businesg, \\
\hline 24. & Theni & Milch animal rearing and milk business, operating food Canteen \\
\hline 25. & Tiruvallur & Garments, washing soap making, dance performance \\
\hline 26. & Tiruvarur & Tea, chicken and petty shops, milch animal rearing \\
\hline 27. & Tiruppur & Garments and related marketing \\
\hline 28. & Thoothukodi & Cow rearing vessels and tiffin centre, stationery and try fish shops \\
\hline 29. & Tiruchirappalli & Beauty parlor, Poultry and petty shops \\
\hline 30. & Vellore & Beeti making, Tiffin shop, garee\& flower business, milk business \\
\hline$\frac{31}{31}$ & Villupuram & phenols, waghing items making and cow rearing and cloth business \\
\hline 32. & Virudhnagar & Making and selling masala items, tiffin centers \\
\hline
\end{tabular}

\section{FINDINGS, SUGGESTIONS AND CONCLUSION}

In the 32 districts in its entirety, all the 506 participants' total economical achievements, before and also after participating in Self Help Teams were examined in the parts of raised revenue and also self employments, gotten very own property, boosted purchasing power of home energies, really good gowns, jewells, quality food, sparing perspectives and also liquidity of cash money. The total influence of all these steps acquired them good life and also public recognition. In the above mentioned parts, before participating in SHGs, 70 per cent participants were extremely low up-and-comers, but after signing up with SHGs, thirteen percent participants were really high achievers. Thus, the scientist comes to the conclusion that by means of pragmatic observation that the
Self Assistance Groups are the only cure all for the Socioeconomic Growth of Transgenders in Tamil Nadu.

\section{SUGGESTIONS}

To the Transgenders: Attempt to follow away from the links of flesh profession and also asking. Also the handicapped and lunatic persons never ever include or even prepared to enter this outrageous as well as illegal business. Transgenders are actually possessing great bodily as well as psychological stamina, therefore they can think about appealing on their own in socially reasonable company tasks. They should not take vengeance to penalize the society, since the culture is not in charge of their tragedy in carried. When they involve themselves in socially accepted business activities along with social awareness the society will definitely prepare to realize all of them. They ought to also acquire instructional as well as specialist certifications. Take all efforts to use concessions extended by the Government as well as the sympathy of the community. When their attitude as well as behavior get the peace of mind of banking companies, they will quickly come forward to satisfy their monetary criteria. When they come out from flesh field and pleading and associate with socially allowed company practices they will definitely get public support, compassion and also co-operation. When they have self confidence as well as mental courage they are going to get worldly wealth as well as will acquire the respect from the society.

To the Authorities: the Federal government is at current offering monetary and psychological support for the Transgender area. The Authorities must provide the basic and higher education so that they will definitely free themselves coming from the age aged unlawful flesh exchange and also begging. The Authorities should set up separate colleges and universities in Transgenders area. The Community considers them undesirable residents and also hence to be dispelled coming from the community. It is actually the great accountability of the Federal governments to give them all possible assistance to find up fiscally as well as get social status as well as lead a suitable lifestyle in the community like any other resident of the nation. The Federal government ought to create them possess health and wellness understanding and provide work adapted learning for Transgenders.

To the Banks: The banks, particularly paled around banking companies ought to supply needed monetary aid to the Transgenders, and also employment possibility have to be actually made for all of them. The Transgenders need to be appropriately qualified to involve on their own in Self Aid Teams and also other self employment tasks. The banking companies need to modify their incorrect idea about the Transgender community that they all possess the same mindset as well as actions. The banker needs to recognize the definitely enthusiastic as well as effort Transgenders as well as provide all monetary and relevant help. The Bankers responsibility performs certainly not end with supplying financings to Transgenders and also they ought to regularly examine their business efficiency and financial location of Transgenders. The banking companies ought to focus a lot more on the beginning and also operating of Self Aid Teams started through Transgender participant

Published By:
Blue Eyes Intelligence Engineering
\& Sciences Publication




\section{XV.CONCLUSION}

The Transgender neighborhood in Tamil Nadu is actually leading a strongly awful lifestyle as well as experiencing all types of barbaric therapies meted out by the civil community. They are disowned by their households, thrown away and condemned by society. Their financial health condition is actually really inadequate and social standing goes to a really low ebb and also there is actually no political celebration or team to look after them. Nowadays the Transgender persons are actually mostly taken part in unlawful prostitution and also sinful pleading to make one thing for their resources. Lately, the popular Authorities and charitable companies are actually handling all of them and are taking some well-being actions as well as tasks to boost the Transgender persons economical and social in fact which will certainly break the ice to the future for their political permission. When the scientist thought and feelings of some remedial solution for the financial as well as social upliftment of Transgenders in Tamil Nadu, the prompt principle that pertained to her mind was the Transgender Personal Aid Group which can easily serve as a relief for the socioeconomic unwell of the Transgenders. Under the existing socioeconomic ailments of the Transgenders, beginning as well as managing the Self Help Groups exclusively for all of them is actually quite an easy one, given that there are actually no step-by-step formalities to become complied with for starting a Personal Aid Team. Even more, the Government is actually giving all sorts of help and also reassurances to begin Personal Help Teams. Transgenders need to have no sizable allotment financing to start the Personal Help Groups and made the rounds financial institutions exist to expand credit score centers to them. The Personal Aid Teams are the only suitable business for the Transgenders Self Help Groups make the Transgender members financially sound with a reputable social condition which might provide also political empowerment in future. The community at large as well as the Authorities must provide the Transgender not only the financial support however likewise the mental commiseration and understanding. The Transgenders ought to be handled passion and consideration. The culture ought to not punish, penalize as well as leave for no error of theirs. The researcher would like to end this research by multiplying an apt Eastern quotation, "Offer a male a fish as well as he are going to consume for a time. Educate a guy to fish and also he is going to consume for the rest of his lifestyle". The Transgenders require the aid of the Authorities as well as community, not in the form of cash and also kind which can nourish all of them for 1 or 2 days, however such as a long-lasting option like starting Personal Aid Groups exclusively for all of them to make sure that they can stand on their personal legs and accomplish economic, social as well as political empowerment in their life.

\section{REFERENCES}

1. Aarmo, Margrete (1999) 'Just how homosexuality came to be 'Un-African': the Scenario of Zimbabwe', in Evelyn Blackwood as well as Saskia E. Wieringa (eds.) Women Wishes: Same-sex Relations and also Transgender Practices around Cultures, pp. 255-80. New York: Columbia University Press.

2. Bureau of democracy, civils rights, and labor, 2010 Country Report on Individual Right Practices, File, April 8, 2011.
3. Pair of Circles web, IANS Chennai, Microfinance program for Transgenders, marginalised girls, 29. Jan, 2010.

4. Literacy as Liberty, Unesco 2003, Published in 2003 by the United Nations Educational, Scientific as well as Cultural Association, 7, Put de Fontenoy, 75352 Paris.

5. The Hindu, Transgender Time Celebrations, April 16, 2012, Chennai

6. Questioning Aravani Activism in Tamil Nadu, Information adjustment, News and evaluation on social compensation and also growth concerns in India. (www.infochangeindia.org).

7. Prabhakar Rajkumar.K, Refinancing assistance of NABARD to Personal Help Teams in Tamil Nadu, Financial finance, Sept. 2006, Web page No: 7 .

8. James E. Miller, Effective Self-help group, article, Posted through Educational Institution of Florida, 19, 2010.

9. Prabhakar Rajkumar.K, Tremendous Growth of SHGs-- Bank links in India, The Economic Challenger, Oct- Dec. 2006, Page 66.

10. Prabhakar Rajkumar.K, Possess Indian Girls Achieved Permission? An Assessment Publication of Small Enterprises Growth Control and also Extension (Sedme) Department of SSI, Govt. of India, Hyderabd-5. Vol.34, No. 1, March 2007, Web page.79.

11. Modifying Attitude (2012), Indian Transgenders bring in a spot in Personal Aid Teams, April 20th, 2012. 